\title{
The Influence of Mathematics Anxiety in Middle and High School Students Math Achievement
}

\author{
Masooma Ali Al Mutawah ${ }^{1}$ \\ ${ }^{1}$ Bahrain Teachers College, University of Bahrain, Kingdom of Bahrain \\ Correspondence: Masooma Ali Al Mutawah, Bahrain Teachers College, University of Bahrain, Southern \\ Governorate, Kingdom of Bahrain. Tel: 973-1743-7297. E-mail: malmutawah@uob.edu.bh
}

Received: December 31, 2014

Accepted: March 6, 2015 Online Published: October 28, 2015

doi:10.5539/ies.v8n11p239

URL: http://dx.doi.org/10.5539/ies.v8n11p239

\begin{abstract}
Math anxiety has been the focus of much psychological and educational research in the past few years, there are many international studies showing that mathematics anxiety is an influence on student's achievements in school, but little research has been done about this issue in Bahrain. Bahrain is a country in the Arabian Gulf region, its economic development is increasing rapidly, and there is currently a focus on improving the school education outcomes to fit the 21st century requirements. Bahrain started a huge curriculum project in September 2013 by changing the primary math curriculum across the country, and will continue the changes to secondary curriculum in the coming years. These changes are intended to improve mathematics education in the country, since Bahraini math scores have been below the international mean for a very long time. This study attempts to investigate if there is a relationship between anxiety and underachieving in mathematics in Bahrain. The Revised Mathematics Anxiety (R-MANX) Survey (Bursal, 2006) was translated into Arabic and administered to 1352 primary students. The data was analyzed to explore the reliability and validity of the translated survey and the associations between Mathematics anxiety and achievement. This paper reports the findings of the study.
\end{abstract}

Keywords: mathematics anxiety, reliability, student's achievement, validity

\section{Introduction}

Yang (2014) wrote "To many people "MATH" is a scary four letter word; they don't like it or feel that they are good at it'. He defines it as 'People who feel tension, apprehension and fear of situations involving math are said to have math anxiety' (p. 28).

Math anxiety in many ways is easy to describe and define: it is the feeling of discomfort and disturbance that some individuals experience when facing mathematical problems. Professor Mark Ashcraft, one of the main researchers in the area, has described it as "Feelings of tension, apprehension, or even dread that interferes with the ordinary manipulation of number and the solving of mathematical problems" (Ashcraft \& Faust, 1994). Like other forms of anxiety, students may feel their heart beat more quickly or strongly, they may believe they are not capable of completing mathematical problems, or they may avoid attempting math courses (Sheffield \& Hunt, 2006).

Developing the mathematics curriculum in Bahrain is one of the main projects that the Ministry of Education is establishing to improve teaching and learning across the country. This project is part of a development program that was started in 2006 to reform the education in Bahrain. Student' performance in mathematics is one of the main concerns of the students, teachers and parents in the country, where there is a common belief that achievement in mathematics is linked to economic development. The schools in the country are adopting different strategies to obtain better out comes in line with the Bahrain 2030 vision for education.

The primary math curriculum was a focus area, and a huge reform project started in April 2011 with all the government institutions related to the primary math education involved. "Bahrain Numeracy Strategy" is basically trying to encourage mental thinking and developing problem solving techniques. The new curriculum was fully implemented in September 2013, and the project is continuing with teacher training and research on the whole picture of math teaching and learning development process in the country. If successful, similar changes will start in secondary schools.

Amy Devine believes that Mathematics anxiety, defined as a state of discomfort associated with performing 
mathematical tasks, affects a notable proportion of the school age population. A 2012 study of 433 British secondary school children, found that secondary school children experience mathematics anxiety, they mentioned that mathematics anxiety warrants attention in the mathematics classroom, particularly because there is evidence that mathematics anxiety develops during the primary school years. They suggested that longitudinal research is needed to investigate the development of mathematics anxiety and its effect on mathematics performance (p. 1).

Furthermore the strong and positive correlations between these two variables highlighted the need to study mathematics anxiety among the students in Bahrain schools. Findings from this study will help the teachers, administrators, and parents to understand the current status of mathematics education and find ways to improve the performance of students in mathematics across all grades.

\section{Literature Review}

Student anxiety in response to mathematics is a significant concern for educators in terms of the perception that high anxiety will relate to avoidance of mathematics (Anderson, 2007, p. 93)

Mathematics is an important subject in school curriculum in every country. From a young age children must learn the basic concepts of mathematics in order to function well in their everyday life (Lebens, Graff, \& Mayer, 2011). Mathematics has been taught so that children can understand the numerical data presented to them, and able to perform simple and complex calculations in day-to-day encounters. It is also common belief among students that mathematics is a hard subject and difficult to learn. In mathematics education, many researchers propose innovative ways of teaching, linking concept and real-life applications and motivating the students to take more interest in the subject to overcome mathematics phobia (Hemmings, Grootenboer, \& Kay, 2011).

As early as 1978, Sepie and Keeling (1978) did a study using regression equations based on the relationship between Otis I.Q. and mathematics achievement; they divided a sample group of 246 children into three groups of over achievers, achievers and under achievers in mathematics. Analysis of variance was used to compare the performances of the three groups on measures of general anxiety, test anxiety and mathematics anxiety. The results of the study showed that the measure of mathematics-specific anxiety differentiated the under achieving group from the other two groups more strongly than the measures of general and test anxiety (p. 15).

In 1990, George Engelhard investigated the relationship of mathematics performance to math anxiety, mother's education and gender; he did a study on 13 years old students from USA and Thailand with a sample of more than 7000 students. He used a 40 -item math performance test as the dependent variable and found that the relationship between math anxiety and mathematics performance was significant in both countries (p. 289).

Harari, Vukovic, and Bailey (2013) did a study to explore the nature of mathematics anxiety in a sample of 106 first grade pupils. The result of their study showed that mathematics anxiety in first grade is a multidimensional construct encompassing: Negative reactions related specifically to foundational mathematical concepts. Numerical confidence related specifically to computation skill. And worry which was not related to any outcome. The levels of mathematics anxiety did not differ by sex or language background.

Karjanto and Yong (2013) studied the level of test anxiety in mathematics subjects among early undergraduate students at the University of Nottingham Malaysia Campus in 2013. The sample was 206 students completed questionnaires on test anxiety exactly before they write their midterm examinations. The level of test anxiety in mathematics was measured using seven Likert questionnaire statements adapted from the Test Anxiety Inventory describing one's emotional feeling before the start of an examination. The result shows that the students who had a lower score expectation were more anxious than those who had a higher score expectation, but they obtained a better score than the expected score.

Sheffield, David, Hunt, and Thomas (2006) did a study and based on it and on other studies of other researchers, they concluded that it is clear that math anxiety has a direct effect on performance of math tasks. These effects are greatest when a secondary task is being completed; this might be akin to a distraction within lectures or testing situations or completing a more complex calculation that involves retaining part of the calculation in memory.

In 2001, Ashcraft and Kirk (2001) studied the relationships among memory, math anxiety, and performance. They found that those individuals who have high math anxiety demonstrate smaller working memory spans, which mean when they are assigned a computation task their reduced working memory capacity will increase their errors. They suggested more empirical attention to be given to math anxiety.

In 2015, Amanda Andrews and Jennifer Brown studied the effects of math anxiety on 80 freshmen students at a university in the southeastern United States. They conducted an observational study using pre-existing data from 
the Freshman Orientation Survey, which contained the 9-item Abbreviated Math Anxiety Scale, and institutional research data. The results suggest that standardized test scores and math anxiety had a moderate, negative relationship.

There are many more recent studies finding a similar relationship between anxiety and achievement within the past decade (Hodges \& Kim, 2013; Adelson \& McCoach, 2011; Chamberlin, 2010; Dumias, 2009; Ismail \& Awang, 2008; Zan et al., 2006; Leder \& Grootenboer, 2005; Tapia \& Marsh, 2004; Hannula, 2002; Singh et al., 2002; Randel et al., 2000; Ruffell, 1998).

How to get students past math anxiety was a concern to Scarpello (2007) who thinks that math anxiety can begin as early as the fourth grade and peaks in middle and high school. He wrote an article saying that math anxiety can be caused by past classroom experiences, parental influences, and remembering poor past math performance. $75 \%$ of Americans stop studying math before they have completed the educational requirements for their career or job according to the National Research Council. He wrote that "research shows that students who have high levels of math anxiety have lower levels of math achievement and may be less likely to pursue math courses or math related careers" (p. 34). So he suggested that "teachers should be aware that students may suffer from math anxiety and they should employ effective teaching methodologies to lessen math anxiety in their classroom" (p. $35)$.

In another study for Taylor and Fraser (2013), they collected data from 745 high-school students from grades 9-12 in 34 classes from four schools in the Southern California area. They used learning environment instrument and an updated Revised Mathematics Anxiety Rating scale. They found significant associations between anxieties and learning environment, they defined the learning environment as 'the social, psychological, and pedagogical contexts in which learning occurs and which affect student achievement and attitudes'.

Teachers also might face mathematics anxiety which may influence what and how they teach in their classrooms. In 2015 Eugene Geist examine training teachers attitude towards mathematics and found that math anxiety affects how teachers assess their ability at mathematics. He also found that confident teachers are more likely to use developmentally appropriate methods of teaching mathematics. The study suggested that in-service trainings should take place to add a focus on teachers' confidence in mathematics to enhance the mathematics outcomes for children and their ability and enjoyment of mathematics.

From the literature review we found that there are no enough studies about mathematics education in Bahrain, and very few researchers studied the role of anxiety in underachieving in mathematics in Bahrain. We thought it was important to find a valid Arabic language instrument that could study math anxiety in Bahrain schools to highlight this and other hidden problems.

\section{Context}

The education system in Bahrain follows a 6-3-3 system. The primary level covers six years and is divided into two cycles. This is followed by three years of intermediate and then three years of secondary education in various tracks of subject disciplines. Schooling in Bahrain is non-compulsory, so all school age children attend voluntarily either in public or private schools.

According to the 2012/2013 school year statistics there are a total of 57 intermediate and 39 high schools all over the country. Schools in Bahrain are segregated by gender, so there are 48 boys schools and 48 girls schools. There are 32560 students in intermediate, 16355 boys and 16205 girls. There are 31294 students in high school, 15335 boys and 15959 girls. The students' ratio between boys and girls are approximately the same. The medium of instruction at all levels is Arabic. The government of the Kingdom of Bahrain always strives to improve the education system by making schools and learning institutions a priority. The recent wave of educational reform efforts and school improvement programs reflects the commitment of the government in increasing capacity and building social capital.

To compare the time spent in teaching math in schools with math proficiency, we checked the TIMSS math results for grade eight in 2011, and found that the teaching hours per year for mathematics in Bahrain for grade 8 was 142 hours and Bahrain mean score in math was 409. Comparing that to some other countries in 2011, we found that Australia yearly teaching hours number was 143 but it's mean was 505, England had 116 hours with a mean of 507, Japan had 108 hours with a mean of 570 and finally Singapore had only 138 teaching hours but with a mean of 611 ! This implies that the total number of hours spent in teaching math might not be the main reason for low achievement in Bahrain; there might be other reasons for that could be the quality of instruction.

If we go over Bahrain's TIMSS results in Math for grade 8 as an example in 2011, out of 97 primary schools, 95 schools participated in the exam, $98 \%$ of within-schools students participated for a total of 4640 students 
assessed. The mean of mathematics achievement overall in Bahrain was 409 with a standard deviation of 100 . Bahrain scored 409 compared to the international average of 478, while the TIMSS average was 500 ! This mean Bahrain needs to work harder to compete internationally to improve its average math scores.

Each successive TIMSS assessment has shown a strong positive relationship within countries between student attitudes toward mathematics and their mathematics achievement. Students were scored according to their degree of agreement with five statements on the Students Like Learning Mathematics scale. The $24 \%$ of Bahrain students who said they "like learning mathematics" scored an average achievement of 454 , while the $38 \%$ who said they "somewhat like learning mathematics" scored average achievement of 413 . The $38 \%$ who said they "do not like learning mathematics" scored an average achievement 381 .

Internationally, on average only 14 percent of eighth grade students expressed confidence in their mathematics ability. The other students were divided approximately equally between those expressing some confidence (45\%) and those expressing little confidence (41\%) (TIMSS, p. 340). Students were scored according to their degree of agreement with nine statements on the Students Confident in Mathematics scale. Bahrain students showed confident were $16 \%$ with average achievement of 490 , who showed somewhat confident were $45 \%$ with average achievement of 417, and who showed no confident were $39 \%$ with average achievement of 372 .

TIMSS also presented the results of how students value mathematics on a scale addressing six different aspects of valuing mathematics. Internationally on average eight grade students placed a high value on mathematics. Students who said they valued mathematics typically had higher achievement than students who only valued it somewhat (TIMSS, p. 329). In Bahrain 48\% said they value mathematics with an average achievement of 425 , $36 \%$ said they somewhat value mathematics with an average of 411 , and finally $16 \%$ said they don't value mathematics with an average of 372 .

The performance on the International Benchmarks of Mathematics Achievement showed that $1 \%$ of the students who participated in the exam in Bahrain achieved advanced benchmark, $8 \%$ achieved high benchmark, $26 \%$ achieved intermediate benchmark, and 53\% achieved low benchmark.

In 2007 Bahrain mean result in TIMSS was 398, and even though Bahrain scored better in 2011,we can still see that the result does not satisfy the Bahrain educational vision and effort to reform the education for a real competitive results.

\section{Research Aims}

This study aims to determine the reliability and validity of the translated Revised Mathematics Anxiety (R-MANX) Survey when used with the students in Bahrain schools.

The study also explores the relationships between mathematics anxiety and achievements for middle and high school students.

\section{Method}

This study is of a quantitative nature since we are looking for the number of students who have Math Anxiety and low math grades. The R-MANX Survey was used to collect data from the students. The survey contains 30 statements, each rated by the respondent on a 1 (never) to 5 (always) scale. The statements describe everyday life and academic situations requiring mathematical thought or tasks and are rated as to the degree of anxiety that respondents perceived they would experience in the given situations (Bursal, p. 173). The survey was developed by Bursal and Paznokas (2006). For the purpose of this study, the R-MANX Survey items were translated into Arabic. The translated version of the questionnaire was checked by Arabic language expert to ensure that the language was suitable for intermediate and high school students.

The survey was first pilot tested before administering to a larger cohort of students. The analysis of the pilot study showed that the instrument has reliability Cronbach Alpha coefficient of 0.859 which is considered to be acceptable. In order to achieve high reliability some problematic statements were adjusted for better comprehension.

The survey was introduced to Grade 8, 9 and 10 students in 14 middle and high schools across Bahrain. Out of all the respondents the useable data from 1352 students was obtained. The data was examined to explore the reliability and validity of the survey, as well as any association between mathematics attitudes and student achievements.

\subsection{Participants and Procedures}

The participants in the study comprised four hundred and eight 8 th graders $(30.2 \%)$, three hundred and ninety-two 9th graders $(29 \%)$, three hundred and one 10th graders $(22.3 \%)$ and two hundred and fifty 11 th 
graders (18.5\%) attending schools in the Kingdom of Bahrain. There were 746 (55.2\%) females and 605 (48.8\%) males.

\subsection{Measures}

The Revised-Mathematics Anxiety Survey (R-MANX: Bursal \& Paznokas, 2006) was used to obtain data from 1351 students who were attending high schools in Bahrain. Students were asked to respond to the R-MANX questionnaire to determine their mathematics anxiety levels. The students were asked to choose one of the five situations which are: 'never', 'rarely', 'sometimes', 'frequently' and 'always' for each of the 30 items in the R-MANX anxiety scale. The answers were scored from 1 to 5 respectively while calculating the scores. Low scores indicated low level of mathematics anxiety and high scores indicated high level of mathematics anxiety according to the total score of the results. In this study total anxiety levels were classified as 'low level of anxiety', 'medium level of anxiety' and 'high level of anxiety'. The classification was made according to the percentiles of the mathematics anxiety scores. Students whose scores were in the lower $33 \%$ were considered in the low mathematics anxiety group. Those whose scores fell between $33 \%$ and $67 \%$ were considered the medium group and students who scored in the upper $33 \%$ were considered to be in the high mathematics anxiety group.

\subsection{Data Analysis}

The interrelationships among the set of variables of the R-MANX were explored using exploratory factor analysis (EFA). Confirmatory factor analysis (CFA) was used to confirm specific hypotheses concerning the structure underlying the set of variables of the R-MANX. EFA was performed on the sample using SPSS version 22. Principal components analysis (PCA) was used to extract the factors followed by oblique rotation of factors using Oblimin rotation.

CFA using maximum likelihood estimation was conducted on the sample using AMOS Version 22 (Arbuckle, 2013) to evaluate model fit. A good model fit can be indicated by a non-significant chi-square (Pallant $\&$ Bailey, 2005), however, other factors can influence this figure, and so as recommended by Hair, Black, Babin \& Anderson (2010), Harrington (2009) and Kline (2010), several fit indices were used to measure model fit. For the incremental fit statistics (Goodness of Fit Index: GFI; the Tucker-Lewis Index: TLI; and the Comparative Fit: CFI) values between .90 and .95 indicate reasonable fit and values between .95 and 1.00 indicate good fit (Tabachnick \& Fidell, 2007). Standardized root mean square residual (SRMR) is another absolute fit index commonly referred to. For the SRMR, value of less than 0.05 would indicate a well-fitting model (Byrne, 2010). The Root Mean-Square Error of Approximation (RMSEA) is described by Byrne (2010) as the most informative statistic in determining model fit as it takes into account the number of variables that are estimated in the model. The RMSEA values between .05 and .08 indicate reasonable fit and values of less than or equal to .05 would indicate a good fit (Kline, 2010).

One-way ANOVA tests and Tukey Honestly Significant Difference (HSD) test were used to explore the impact of grade levels (Grade 8, 9, 10) and also levels of achievement $(0-59 \%, 60-69 \%, 70-79 \%, 80-89 \%, 90-100 \%)$ on levels of anxiety (low, medium, high), and effect sizes were calculated for each comparison. Also two-way ANOVA was used to compare the anxiety scores for the impact of grade level and gender on anxiety.

\section{Results}

\subsection{Descriptive Statistics}

Some descriptive statistics of the R-MANX items are shown in Appendix 1. The mean score ranged from 2.22 to 3.39. All the standard deviations (SD) were above 1.00 (1.42 to 1.63), indicating a large spread of item scores around the mean.

As recommended by Tabachnick and Fidell (2007), the data was examined for multivariate normality, multicollinearity and outliers before assessing the factor structure of the responses. The bivariate correlations, tolerance, and variance inflation values indicated that neither bivariate nor multivariate multicollinearity was present. Because maximum likelihood estimation assumes multivariate normality of the observed variables, the data were examined with respect to univariate and multivariate normality.

\subsection{Reliability Measures}

Item reliability of each measure, composite reliability of each construct, and the average variance extracted were examined, in order to assess the convergent validity of the measurement items in relation to their constructs. The interpretation of the composite reliability is similar to that of Cronbach's alpha, except that it takes into account the actual factor loadings rather than assuming that each item is equally weighted in the composite load determination. Table 1 shows that the reliabilities of all the constructs ranged from .86 to .95 , which are above 
the minimum value of .70 . Table 1 also reports the inter-construct correlations and square root of average variance extracted. The results support the discriminant validity because, for each construct, the square root of the AVE is larger than inter-construct correlation.

Table 1. Construct reliability and average variance extracted

\begin{tabular}{llllll}
\hline Construct & CR & AVE & Component 1 & Component 2 & Component 3 \\
\hline Component 1 & .95 & .69 & $\mathbf{( 0 . 8 3 )}$ & & \\
Component 2 & .87 & .52 & $.25^{* *}$ & $\mathbf{( 0 . 7 2 )}$ & \\
Component 3 & .86 & .51 & $.51^{* *}$ & $.13^{* *}$ & $\mathbf{( 0 . 7 1 )}$ \\
Mean & & & 37.27 & 18.11 & 14.06 \\
SD & & & 12.54 & 5.12 & 5.34 \\
\hline
\end{tabular}

$* * p<0.01$;

Average variance extracted (AVE) is computed by $\sum \lambda^{2} / \sum \lambda^{2}+\sum\left(1-\lambda^{2}\right)$;

Construct reliability (CR) is computed by $\left(\sum \lambda\right)^{2} /\left(\sum \lambda\right)^{2}+\sum\left(1-\lambda^{2}\right)$, where $\lambda=$ standardized loadings.

\subsection{Convergent Validity}

Convergent validity measures the correlations of items in a single construct to ensure that items are correlated and measure the same underlying dimensions. As proposed by Fornell and Larcker (1981), item reliability of each measure, composite reliability of each construct, and the average variance extracted were examined, in order to assess the convergent validity of the measurement items in relation to their constructs. The interpretation of the composite reliability is similar to that of Cronbach's alpha, except that it takes into account the actual factor loadings rather than assuming that each item is equally weighted in the composite load determination. Barclay, Higgins, and Thompson (1995) and Hair, Black, Babin, and Anderson (2010) suggested that regarding reliability at the item level, the minimum requirement suggested for factor loading is 0.7 . The results in Appendix 2 report that most of the factor loadings were above the recommended cut-off point. Thus, convergent validity was satisfactory at the item level.

\subsection{Exploratory Factor Analysis}

The 30 items of the R-MANX were subjected to principal components analysis (PCA) using SPSS version 22 (see Appendix 2). We assessed the suitability of data for factor analysis by first inspecting the correlation matrix for evidence of coefficients greater than .3, as recommended by Tabachnick and Fidell (2007). The inspection of the correlation matrix revealed the presence of many coefficients of .3 and above, indicating that factor analysis may be appropriate. To help assess the factorability of the data two statistical measures were generated by SPSS, namely, Bartlett's Test of Sphericity (Bartlett, 1954), and the Kaiser-Meyer-Olkin (KMO) measure of sampling adequacy (Kaiser, 1960). The KMO value was .94, which exceeds the recommended value of .6 (Kaiser, 1960) and the Bartlett's Test of Sphericity (Bartlett, 1954) was statistically significant, supporting the factorability of the correlation matrix.

Principal component analysis (PCA) was used to extract the factors followed by oblique rotation of factors using Oblimin rotation. PCA revealed the presence of five components with eigenvalues exceeding $1(7.73,2.02,1.88$, $1.10,1.04)$. These five components explained a total of 45.89 percent of the variance.

\subsection{Scores of Mathematics Anxiety Scale according to Grade Levels}

One-way between-groups analysis of variance was conducted to explore the impact of grade levels on mathematics anxiety of students, as measured by R-MANX (low, moderate, high). Subjects were students in Grades $8,9,10$, and 11 . There was a statistically significant difference at the $p<.05$ level in R-MANX scores for the four grade levels: $\mathrm{F}(3,382)=9.09, p=.00$. The effect size was .07 , and it was calculated using eta squared. This effect is considered a medium effect size, according to Cohen (1992), who classifies .01 as a small effect, .06 as a medium effect and .14 as a large effect. Post-hoc comparisons using the Tukey HSD test indicated that the mean score for Grade $8(\mathrm{M}=81.88, \mathrm{SD}=17.99)$ was significantly different from Grade $9(\mathrm{M}=84.41$, $\mathrm{SD}=18.67)$ and Grade $11(\mathrm{M}=77.43, \mathrm{SD}=17.42)$. Grade 9 was significantly different from both Grade $10(\mathrm{M}$ $=82.88, \mathrm{SD}=19.36$ ) and Grade 11. Grade 8 did not differ significantly from Grade 10. Also Grade 10 did not differ significantly from Grade 11. The mean scores indicated that Grade 11 students had higher anxiety scores 
than the students of the other grade levels. The students with the lowest anxiety scores were Grade 9 students. One-way ANOVA test and Tukey multiple comparison test results are reported in Table 1.

Table 3. One-way ANOVA and Tukey test results for scores of Mathematics anxiety according to grade levels

\begin{tabular}{|c|c|c|c|c|c|c|c|c|c|c|}
\hline & $\begin{array}{l}\text { Sum of } \\
\text { Squares }\end{array}$ & df & $\begin{array}{l}\text { Mean } \\
\text { Square }\end{array}$ & $\mathrm{F}$ & Sig & \multicolumn{2}{|c|}{ Tukey HSD } & $\begin{array}{l}\text { Mean } \\
\text { Difference }\end{array}$ & $\begin{array}{l}\text { Standard } \\
\text { Error }\end{array}$ & Sig \\
\hline $\begin{array}{l}\text { Between } \\
\text { Groups }\end{array}$ & 16.633 & 3 & 5.54 & 9.09 & .000 & \multirow[t]{3}{*}{ Grade 8} & Grade 9 & $.30^{*}$ & .112 & .040 \\
\hline $\begin{array}{l}\text { Within } \\
\text { Groups }\end{array}$ & 233.11 & 382 & .61 & & & & Grade 10 & -.09 & .106 & .824 \\
\hline \multirow[t]{10}{*}{ Total } & 249.74 & 385 & & & & & Grade 11 & $-.32 *$ & .113 & .026 \\
\hline & & & & & & \multirow[t]{3}{*}{ Grade 9} & Grade 8 & $-.30^{*}$ & .112 & .040 \\
\hline & & & & & & & Grade 10 & $-.39 *$ & .114 & .004 \\
\hline & & & & & & & Grade 11 & $-.62 *$ & .121 & .000 \\
\hline & & & & & & \multirow[t]{3}{*}{ Grade 10} & Grade 8 & .09 & .106 & .824 \\
\hline & & & & & & & Grade 9 & $.39^{*}$ & .114 & .004 \\
\hline & & & & & & & Grade 11 & -.23 & .114 & .195 \\
\hline & & & & & & \multirow[t]{3}{*}{ Grade 11} & Grade 8 & $.32 *$ & .113 & .026 \\
\hline & & & & & & & Grade 9 & $.62 *$ & .121 & .000 \\
\hline & & & & & & & Grade 10 & .23 & .114 & .195 \\
\hline
\end{tabular}

$p<.05$.

\subsection{Scores of Mathematics Anxiety Scale according to Achievement}

One-way between-groups analysis of variance was conducted to explore the impact of levels of achievement $(0-59 \%, 60-69 \%, 70-79 \%, 80-89 \%, 90-100 \%)$ on levels of mathematics anxiety, as measured by R-MANX. The students were assessed on their demonstration of specific knowledge mathematics skills, and were divided into five groups. Group 1: Students who scored 0-59\%, demonstrating no effectiveness; Group 2: 60-69\%, demonstrating limited effectiveness; Group 3: 70-79\% demonstrating some effectiveness; Group 4: 80-89\%, demonstrating considerable effectiveness and Group 5: Students who scored $90-100 \%$, demonstrating high degree of effectiveness.

There was a statistically significant difference at the $p<.05$ level in R-MANX scores for the five achievement groups: $\mathrm{F}(4,381)=7.23, p=.000$. The effect size was .076 , and it was calculated using eta squared. This effect is considered a medium effect size, according to Cohen (1988). Post-hoc comparisons using the Tukey HSD test indicated that the mean score for Group $1(\mathrm{M}=2.44, \mathrm{SD}=.71)$ was significantly different from Group $5(\mathrm{M}=$ $1.67, \mathrm{SD}=.76)$, Group $4(\mathrm{M}=1.93, \mathrm{SD}=.84)$ and Group $3(\mathrm{M}=2.00, \mathrm{SD}=.76)$. Group $2(\mathrm{M}=2.17, \mathrm{SD}=.78)$ was significantly different from Group 5. Also Group 3 was significantly different from Group 5. Group 2 did not differ significantly from Group 1, Group 3 and Group 4. Similarly, Group 4 was not significantly different from either Group 3 or 5. According to the Tukey test performed to determine the level at which the difference exists, mathematic anxiety of the students with low level of mathematics achievement was higher than those students with higher level of mathematics achievement. The results of the one-way ANOVA test and Tukey multiple comparison test results are reported in Table 2.

\section{Discussion and Conclusion}

This study attempted to validate the instrument used to measure the mathematic anxiety among students. The Revised Mathematics Anxiety (R-MANX) survey was translated into Arabic and administered to 1352 students from the middle and high schools across Bahrain. Mathematics anxiety has been recognized as one of the key psychological factors that can influence the academic outcomes of the students. The descriptive statistics of the R-MANX show that the instrument is reliable and valid to use in the Bahrain context. The factor analysis revealed that the instrument contains three constructs and the reliabilities of each construct ranges from .86 to .95 . These reliability indices are higher than the accepted levels and the results indicate that R-MANX is a robust 
instrument that researchers can use with confidence.

The literature search shows that no instruments exist to measure the mathematics anxiety and no studies have been done in this context. This pioneering attempt provides opportunities for other researchers to explore other grade levels and schools across the country. The findings from this study are also timely in order to inform the administrators and educational planners of educational reforms, the design of new curriculum and adopting relevant instructional strategies to overcome the anxiety of the students. This study is limited to students in Grades 8, 9, 10 and 11 and covers 14 middle and high schools only. Further studies could be done to cover other grade levels and schools. It will be interesting to see the differences in rural and urban schools, and the gender differences in mathematics anxiety among students. The results from this study show the statistically significant grade level differences. Grade 11 students had the highest mean anxiety score. This means that the level of anxiety increases as the students progress through the grade levels. It may also be due to the complexity of the mathematics curriculum where more advanced concepts are introduced at the higher level. These results may also have an impact on the way mathematics is taught in the lower grade levels. Teachers need to use instructional strategies that are suitable for the cognitive abilities of the students and progression of the content should be gradual.

This study also found correlations between the level of mathematics anxiety and students' perceived achievement. The students were asked to indicate where they stand in terms of level of mathematics achievements giving the five scales that range from the lowest to the highest. The analysis of the results shows that the level of the anxiety is the highest among those who perceived themselves as low achievers.

This research made two major contributions to the mathematics education in Bahrain. The study established that the Arabic version of R-MANX survey can be used as a reliable and valid instrument in this context. The study also confirmed the relationships between the anxiety and achievement among middle and high school students in Bahrain. Mathematics anxiety is one of the many possible factors that can affect students' achievement in the subject. Since students learning and success in education is complex and depends on many other factors, educators increasingly look at multiple aspects in the teaching and learning process. These include non-cognitive factors such as beliefs, perseverance, goal-orientation, and self-esteem, which some studies show the influence of such factors in students' educational success. Future research efforts should consider exploring how other non-cognitive factors can influence the educational outcomes in this context. We hope that findings from this study will assist teachers and administrators to design conducive learning environments in which student can enjoy the learning process and produce better results.

\section{References}

Adelson, J. L., \& McCoach, D. B. (2011). Development and psychometric properties of the Math and Me Survey measuring third through sixth graders' attitudes toward mathematics. Measurement and evaluation in counselling and development, 44(4), 225-247. http://dx.doi.org/10.1177/0748175611418522

Ader, E., \& Erktin, E. Coping as Self-Regulation of Anxiety: A Model for Math Achievement in Highstakes Tests. Cognition, Brain, Behavior. An Interdisciplinary Journal, 14(4), 311-332.

Anderson, V. (2007). An Online Survey to Assess Student Anxiety and Attitude Response to Six Different Mathematical Problems. Launceston College and University of Tasmania. Mathematics: Essential Research, Essential Practice, 1, 93-102.

Andrews, A., \& Brown, J. (2015). The effects of math anxiety. Education, 135(3), 362-370.

Arbuckle, J. L. (2013). Amos (version 22) [Computer Program]. Chicago: SPSS.

Ashcraft, M. H., \& Kirk, E. P. (2001). The relationships among working memory, math anxiety, and performance. Journal of Experimental Psychology, 130(2), 224-237. http://dx.doi.org/10.1037/0096-3445.130.2.224

Ashcraft, M. H., \& Faust, M. W. (1994). Mathematics anxiety and mental arithmetic performance: An $\begin{array}{llll}\text { exploratory investigation. Cognition and } & \text { Emotion, }\end{array}$ http://dx.doi.org/10.1080/02699939408408931

Bartlett, M. S. (1954). A note on the multiplying factors for various chi square approximations. Journal of the Royal Statistical Society, 16 (Series B), 296-298.

Bursal, M., \& Paznokas, L. (2006). Mathematics anxiety and preservice elementary teachers' confidence to teach mathematics and science. School Science and Mathematics, 104(6), 173-180. http://dx.doi.org/10.1111/j.1949-8594.2006.tb18073.x

Byrne, B. M. (2010). Structural equation modelling with AMOS: Basic concepts, applications, and 
programming. Routledge, Taylor \& Francis group.

Chamberlin, S. A. (2010). A review of instruments created to assess affect in mathematics. Journal of Mathematics Education, 3(1), 167-182.

Devine, A., \& Fawcett, K., Szucs, D., \& Dowker, A. (2012). Gender differences in mathematics anxiety and the relation to mathematics performance while controlling for test anxiety. Behavioral and Brain Functions, 8(33), 1-9. http://dx.doi.org/10.1186/1744-9081-8-33

Dumais, S. A. (2009). The academic attitudes of American teenagers, 1990-2002: Cohort and gender effects on $\begin{array}{llll}\text { math } & \text { achievement. Social }\end{array}$ http://dx.doi.org/10.1016/j.ssresearch.2009.05.010

Erden, M., \& Akgul, S. (2010). Predictive Power of Math Anxiety and Perceived Social Support from Teacher for Primary Students' Mathematics Achievement. Journal of Theory and Practice in Education, 6(1), 3-16.

Geist, E. (2015). Math anxiety and the "math gap": How attitudes toward mathematics disadvantages students as early as preschool. Education, 135(3), 328-336.

George, E. J. (1990). Math Anxiety, mother's and the Mathematics Performance of Adolescent Boys and Girls: Evidence from the United States and Thailand. The Journal of Psychology, 124(3), 289-298.

Hair, J., Black, W., Babin, B., \& Anderson, R. (2010). Multivariate Data Analysis (7th ed.). Upper Saddle River, New Jersey: Prentice-Hall.

Hannula, M. S. (2002). Attitude towards mathematics: Emotions, expectations and values. Educational Studies in Mathematics, 49(1), 25-46. http://dx.doi.org/10.1023/A:1016048823497

Harari, R. R., Vukovic, R. K., \& Bailey, S. P. (2013). Mathematics anxiety in young children: an exploratory study. The journal of experimental education, 81(4), 538-555. http://dx.doi.org/10.1080/00220973.2012.727888

Harrington, D. (2009). Confirmatory Factor Analysi. New York, NY: Oxford University Press.

Hemmings, B., Grootenboer, P., \& Kay, R. (2011). Predicting mathematics achievement: The influence of prior achievement and attitudes. International Journal of Science and Mathematics Education, 9(3), 691-705. http://dx.doi.org/10.1007/s10763-010-9224-5

Hodges, C., \& Kim, C. (2013). Improving college students' attitudes toward mathematics. TechTrends, 57(4), 59-65. http://dx.doi.org/10.1007/s11528-013-0679-4

Ismail, N. A., \& Awang, H. (2008). Assessing the effects of students' characteristics and attitudes on mathematics performance. Problems of Education in the 21st Century, 9.

Kaiser, H. F. (1960). The application of electronic computers to factor analysis. Educational and Psychological Measurement, 20, 141-151. http://dx.doi.org/10.1177/001316446002000116

Karjanto, N., \& Yong, S. T. (2013). Test anxiety in mathematics among early undergraduate students in a British university in Malaysia. European Journal of Engineering Education, 38(1), 11-37. http://dx.doi.org/10.1080/03043797.2012.742867

Kesici, S., \& Erdagan, A. (2010). Mathematics Anxiety According to Middle School Students' Achievement Motivation and Social Comparison. Education, 131(1), 54-63.

Kesici, S., \& Erdagan, A. (2011). Prediction of High School Students' Mathematics Anxiety by Their Achievement Motivation and Social Comparison. Elementary Education Online, 10(2), 646-652.

Kline, R. B. (2010). Principles and practice of structural equation modeling (3rd ed.). New York: Guilford Press.

Lebens, M., Graff, M., \& Mayer, P. (2010). The affective dimensions of mathematical difficulties in schoolchildren. Education Research International, 2011.

Leder, G., \& Grootenboer, P. (2005). Affect and mathematics education. Mathematics Education Research Journal, 17(2), 1-8. http://dx.doi.org/10.1007/BF03217413

Levine, G. (2008). A Foucaultian Approach to Academic Anxiety. Educational Studies, 44, 62-76. http://dx.doi.org/10.1080/00131940802225101

Ministry of Education. (2013). Bahrain Kingdom, reports and statistics. Retrieved from http://www.moe.gov.bh/en/statistics.aspx 
Mullis, I. V. S., Martin, M. O., Foy, P., \& Arora, A. (2012). TIMSS 2011 International Results in Mathematics. Chestnut Hill, MA: TIMSS \& PIRLS International Study Center, Boston College, USA.

Pallant, J. F., \& Bailey, C. M. (2005). Assessment of the structure of the hospital anxiety and depression scale in musculoskeletal patients. Health and Quality of Life Outcomes, 3(82), 1-9.

Randel, B., Stevenson, H. W., \& Witruk, E. (2000). Attitudes, beliefs, and mathematics achievement of German and Japanese high school students. International Journal of Behavioral Development, 24(2), 190-198. http://dx.doi.org/10.1080/016502500383313

Ruffell, M., Mason, J., \& Allen, B. (1998). Studying attitude to mathematics. Educational Exchange Quarterly, $8(2), 16-21$.

Sarah, S. et al. (2012). Math Anxiety in Second and third Graders and its relation to Mathematics Achievement. Frontiers in Psychology, 3, 1-12.

Scarpello, G. (2007). Helping Students Get Past Mathematics Anxiety. Techniques: Connecting Education and Careers, 82(6), 34-35.

Sepie, A. C., \& Keeling, B. (1978). Types of Anxiety and Under-Achievement in Mathematics. The Journal of Educational Research, 72(1), 15-19. http://dx.doi.org/10.1080/00220671.1978.10885111

Sheffield, D., \& Hunt, T. (2006). How Does Anxiety Influence Maths Performance and What Can We do About It? Retrieved from http://journals.heacademy.ac.uk/doi/full/10.11120/msor.2006.06040019

Singh, K., Granville, M., \& Dika, S. (2002). Mathematics and science achievement: Effects of motivation, interest, and academic engagement. The Journal of Educational Research, 95(6), 323-332. http://dx.doi.org/10.1080/00220670209596607

Tabachnick, B. G., \& Fidell, L. S. (2007). Using multivariate statistics (5th ed.). Boston: Pearson Education.

Tapia, M., \& Marsh, G. E. (2004). An instrument to measure mathematics attitudes. Academic Studies in Mathematics, 35(1), 1-18.

Taylor, B. A., \& Fraser, B. J. (2013) Relationships between learning environment and mathematics anxiety, Learning Environ Res, 16, 297-313. http://dx.doi.org/10.1007/s10984-013-9134-x

Yang, J. (2014). Math Anxiety: Can teachers help students reduce it? American educator, 28-43. Retrieved from https:/hpl.uchicago.edu/sites/hpl.uchicago.edu/files/uploads/American\%20Educator,\%202014.pdf

Zakaria, E., \& Norazah, M. N. (2008). The Effects of Mathematics Anxiety on Matriculation Students as Related to Motivation and Achievement. Eurasia Journal of Mathematics, Science \& Technology Education, 4(1), 27-30.

Zan, R., Brown, L., Evans, J., \& Hannula, M. S. (2006). Affect in mathematics education: An introduction. Educational studies in mathematics, 63(2), 113-121. http://dx.doi.org/10.1007/s10649-006-9028-2

\section{Appendix A}

Descriptive Statistics of the Items in the R-MANX

\begin{tabular}{|c|c|c|c|c|c|}
\hline & Item & Mean & SD & Skewness & Kurtosis \\
\hline R-MANX1 & $\begin{array}{l}\text { If one of my friends is chosen for answering a question } \\
\text { in math class, I feel happy for not being the chosen } \\
\text { one. }\end{array}$ & 2.78 & 1.47 & .21 & -1.28 \\
\hline R-MANX2 & $\begin{array}{l}\text { I panic when I start the mathematical part of a } \\
\text { standardized achievement test. }\end{array}$ & 2.91 & 1.44 & .08 & -1.30 \\
\hline R-MANX3 & $\begin{array}{l}\text { I cannot ask any question about what I did not } \\
\text { understand in math class. }\end{array}$ & 2.46 & 1.48 & .50 & -.1 .18 \\
\hline R-MANX4 & I like doing math homework & 2.92 & 1.55 & .06 & -1.48 \\
\hline R-MANX5 & I do not like the equations in science courses. & 2.93 & 1.60 & .07 & -1.54 \\
\hline R-MANX6 & $\begin{array}{l}\text { I panic when I get math homework consisting of many } \\
\text { problems. }\end{array}$ & 2.77 & 1.52 & .23 & -1.38 \\
\hline
\end{tabular}




\begin{tabular}{|c|c|c|c|c|c|}
\hline R-MANX7 & $\begin{array}{l}\text { When I hold a math textbook to study I start feeling } \\
\text { stomach ache. }\end{array}$ & 2.52 & 1.56 & .46 & -1.33 \\
\hline R-MANX8 & I cannot concentrate on anything before a math exam. & 2.89 & 1.52 & .09 & -1.41 \\
\hline R-MANX9 & $\begin{array}{l}\text { I want to be the treasurer of the school clubs which I } \\
\text { participate in. }\end{array}$ & 2.22 & 1.48 & .80 & -.86 \\
\hline R-MANX10 & I am afraid of learning my math grade. & 3.03 & 1.53 & -.03 & -1.45 \\
\hline R-MANX11 & $\begin{array}{l}\text { I am afraid of presenting the problems to the teacher } \\
\text { which I can solve. }\end{array}$ & 2.32 & 1.44 & .63 & -1.00 \\
\hline R-MANX12 & $\begin{array}{l}\text { I can reject helping a child with his homework, } \\
\text { because I am afraid of facing a question which I cannot } \\
\text { solve. }\end{array}$ & 2.35 & 1.48 & .64 & -1.04 \\
\hline R-MANX13 & I am afraid of taking a math pop-quiz. & 2.81 & 1.54 & .17 & -1.45 \\
\hline R-MANX14 & $\begin{array}{l}\text { I come to the first day of math classes with hope every } \\
\text { year. }\end{array}$ & 3.39 & 1.47 & -.36 & -1.23 \\
\hline R-MANX15 & $\begin{array}{l}\text { I cannot study well for math exams because I worry } \\
\text { about my grade. }\end{array}$ & 2.93 & 1.54 & .07 & -1.49 \\
\hline R-MANX16 & $\begin{array}{l}\text { When I open my math book and look at the pages, I } \\
\text { fear I will fail the course. }\end{array}$ & 2.98 & 1.63 & .02 & -1.62 \\
\hline R-MANX17 & $\begin{array}{l}\text { I can ask my teacher about a concept, which I did not } \\
\text { understand well, after a math class. }\end{array}$ & 3.45 & 1.49 & -.40 & -1.27 \\
\hline R-MANX18 & $\begin{array}{l}\text { I feel anxious and pessimistic while waiting for the } \\
\text { result of a math exam. }\end{array}$ & 3.26 & 1.52 & -.26 & -1.37 \\
\hline R-MANX19 & $\begin{array}{l}\text { I would rather learn a subject presented with numbers } \\
\text { or graphics than with words. }\end{array}$ & 3.07 & 1.46 & -.08 & -1.30 \\
\hline R-MANX20 & $\begin{array}{l}\text { When I think about the subjects required for passing a } \\
\text { math course, I feel I cannot complete my school } \\
\text { requirements. }\end{array}$ & 2.73 & 1.45 & .23 & -1.27 \\
\hline R-MANX21 & I do not like dealing with numbers. & 2.55 & 1.52 & .43 & -1.28 \\
\hline R-MANX22 & $\begin{array}{l}\text { I feel nervous when one of my friends notices that I } \\
\text { could not understand the solution of a math question. }\end{array}$ & 2.68 & 1.49 & .29 & -1.32 \\
\hline R-MANX23 & I have problems listening to my math teachers. & 2.30 & 1.45 & .68 & -.97 \\
\hline R-MANX24 & $\begin{array}{l}\text { The best parts of the other courses are the parts dealing } \\
\text { with mathematics. }\end{array}$ & 2.76 & 1.42 & .21 & -1.22 \\
\hline R-MANX25 & $\begin{array}{l}\text { I get nervous when I learn that the next lesson is } \\
\text { mathematics. }\end{array}$ & 2.55 & 1.54 & .45 & -1.30 \\
\hline R-MANX26 & I do not like making calculations in everyday life. & 2.63 & 1.44 & .32 & -1.21 \\
\hline
\end{tabular}


R-MANX27 I misunderstand concepts in math courses.

$\begin{array}{lll}2.58 & 1.44\end{array}$

$\begin{array}{llll}3.17 & 1.45 & -.14 & -1.30\end{array}$ for a problem.

$\begin{array}{llll}2.51 & 1.53 & .48 & -1.26\end{array}$

$\begin{array}{llll}2.41 & 1.52 & .56 & -1.19\end{array}$

R-MANX30 Even though I think a salesman made a mistake about the amount of my charge, I cannot object, since I will not be able to make the calculations while somebody is watching me.

\section{Appendix B}

Pattern and structure matrix for PCA with oblimin rotation of three factor solution of R-MANX-30 items

\begin{tabular}{|c|c|c|c|c|c|c|c|}
\hline \multirow[b]{2}{*}{ Item } & \multicolumn{3}{|c|}{ Pattern } & \multicolumn{3}{|c|}{ Structure } & \multirow[b]{2}{*}{$\begin{array}{l}\text { Communaliti } \\
\text { es }\end{array}$} \\
\hline & $\begin{array}{c}\text { Componen } \\
\text { t } 1\end{array}$ & $\begin{array}{c}\text { Componen } \\
\text { t } 2\end{array}$ & $\begin{array}{c}\text { Componen } \\
\text { t } 3\end{array}$ & $\begin{array}{c}\text { Componen } \\
\text { t } 1\end{array}$ & $\begin{array}{l}\text { Compone } \\
\text { nt } 2\end{array}$ & $\begin{array}{c}\text { Component } \\
3\end{array}$ & \\
\hline $\begin{array}{c}\text { R-MANX1 } \\
8\end{array}$ & .84 & -.01 & .13 & .86 & -.14 & -.10 & .52 \\
\hline $\begin{array}{c}\text { R-MANX1 } \\
5\end{array}$ & .80 & -.04 & -.09 & .82 & -.20 & -.31 & .53 \\
\hline $\begin{array}{c}\text { R-MANX1 } \\
0\end{array}$ & .79 & -.04 & .04 & .80 & -.18 & -.17 & .44 \\
\hline $\begin{array}{c}\text { R-MANX1 } \\
6\end{array}$ & .76 & -.11 & -.07 & .78 & -.26 & -.29 & .52 \\
\hline R-MANX8 & .74 & -.03 & -.02 & .75 & -.16 & -.22 & .43 \\
\hline $\begin{array}{l}\text { R-MANX2 } \\
8\end{array}$ & .72 & .20 & .05 & .74 & .09 & -.11 & .36 \\
\hline R-MANX2 & .71 & .14 & -.02 & .72 & .01 & -.20 & .37 \\
\hline $\begin{array}{l}\text { R-MANX1 } \\
3\end{array}$ & .67 & -.08 & -.16 & .68 & -.22 & -.34 & .43 \\
\hline $\begin{array}{l}\text { R-MANX2 } \\
0\end{array}$ & .62 & -.05 & -.29 & .65 & -.18 & -.45 & .45 \\
\hline R-MANX6 & .57 & .03 & -.03 & .58 & -.07 & -.17 & .23 \\
\hline R-MANX7 & .56 & -.15 & -.27 & .57 & -.27 & -.43 & .44 \\
\hline $\begin{array}{l}\text { R-MANX2 } \\
2\end{array}$ & .55 & .20 & -.34 & .55 & .08 & -.44 & .41 \\
\hline
\end{tabular}




\begin{tabular}{|c|c|c|c|c|c|c|c|}
\hline $\begin{array}{l}\text { R_MANX2 } \\
7\end{array}$ & .54 & -.22 & -.22 & .53 & -.35 & -.54 & .50 \\
\hline $\begin{array}{l}\text { R-MANX2 } \\
1\end{array}$ & .34 & -.25 & -.32 & .38 & -.35 & -.45 & .37 \\
\hline R-MANX1 & .34 & -.19 & -.17 & .32 & -.28 & -.29 & .22 \\
\hline R-MANX5 & .31 & .02 & .05 & .29 & -.04 & -.04 & .07 \\
\hline $\begin{array}{l}\text { R-MANX2 } \\
9\end{array}$ & -.28 & .76 & -.32 & -.31 & .79 & -.15 & .51 \\
\hline R-MANX4 & -.15 & .73 & -.04 & -.25 & .76 & .08 & .40 \\
\hline $\begin{array}{l}\text { R-MANX2 } \\
4\end{array}$ & -.10 & .72 & -.25 & -.14 & .72 & -.14 & .36 \\
\hline $\begin{array}{l}\text { R-MANX1 } \\
4\end{array}$ & .21 & .70 & .17 & .05 & .71 & .18 & .33 \\
\hline $\begin{array}{l}\text { R-MANX1 } \\
7\end{array}$ & .16 & .66 & .37 & -.05 & .69 & .38 & .36 \\
\hline $\begin{array}{l}\text { R-MANX1 } \\
9\end{array}$ & .11 & .61 & .01 & .02 & .67 & .04 & .15 \\
\hline $\begin{array}{l}\text { R-MANX3 } \\
0\end{array}$ & .02 & .09 & .75 & .17 & .01 & .79 & .32 \\
\hline R-MANX9 & -.18 & .27 & .74 & -.06 & .23 & .77 & .31 \\
\hline $\begin{array}{l}\text { R-MANX1 } \\
2\end{array}$ & .16 & -.04 & .71 & .33 & -.14 & .75 & .36 \\
\hline $\begin{array}{l}\text { R-MANX2 } \\
3\end{array}$ & .19 & -.10 & .70 & .37 & -.21 & .74 & .40 \\
\hline $\begin{array}{l}\text { R-MANX1 } \\
1\end{array}$ & .18 & -.02 & .62 & .34 & -.12 & .67 & .33 \\
\hline R-MANX3 & .11 & -.10 & .60 & .28 & -.18 & .62 & .30 \\
\hline $\begin{array}{l}\text { R-MANX2 } \\
5\end{array}$ & .36 & -.23 & -.39 & .52 & -.35 & -.53 & .45 \\
\hline $\begin{array}{l}\text { R-MANX2 } \\
6\end{array}$ & .27 & -.26 & -.31 & .42 & -.35 & -.42 & .32 \\
\hline
\end{tabular}

Note. Bolded items indicate major loadings for each item. 


\section{Copyrights}

Copyright for this article is retained by the author(s), with first publication rights granted to the journal.

This is an open-access article distributed under the terms and conditions of the Creative Commons Attribution license (http://creativecommons.org/licenses/by/3.0/). 